\title{
BIOESTRATIGRAFIA DO GRUPO PASSA DOIS NO ESTADO DE SÃO PAULO*
}

\author{
Geólogo SERGIO MEZZALIRA - Pesquisador Científico
}

\begin{abstract}
The well drilling to get groundwater supply in São Paulo State has been carried by Instituto Geológico (ex-Instituto Geográfico e Geológico). It led not only to new stratigraphic data but also, to paleontologic observations which has enlarged broadly our knowledge on geology concerning to Passa Dois Group in São Paulo State.

The following fossils found in Lara wells have been identified: Lycopodiopsis derbyi Renault; ? Thallites sp.; Pecopteris sp.; Unknown fossils plants; Leinzia froesi Mendes; Paulocaris pachecoi Clarke; Amaralia paulistana Kegel; Liocaris huenei Beurlen; Clarkecaris brazilicus (Clarke) Mezzalira; and others as fish scales and spines from Paleoniscidea and Ostracoda.

Then some considerations are done concerning to the biota fossil stratigraphic position in Passa Dois Group. The recent survey in this area led to the correlation between macro and microfossil, including the bioestratigraphic zoning. It has been suggested in experimental way the possible correlation and the respective zones which follow: Pinzonella neotropica Zone; Lycopodiopsis derbyi Zone; Zone I; Pinzonella illusa Zone; Zone II; in Estrada Nova Formation. It has been suggested in the underlying Iraty Formation which includes Serra Alta Member the Zone III; Leinzia froesi Zone; Barbosaia angulata Zone; Paulocaris pachecoi Zone; Mesosaurus brasiliensis Zone including Pygaspis brasiliensis Sub-Zone and Clarkecaris brazilicus Zone.
\end{abstract}

\section{RESUMO}

A abertura de poços, para captação de água subterrânea, em diversas localidades do Estado de São Paulo, pelo Instituto Geológico (ex-Instituto Geográfico e Geológico), tem-nos fornecido novos dados litológicos e paleontológicos que permitem ampliar o conhecimento e comportamento geopaleontológico do Grupo Passa Dois no Estado de São Paulo.

Foram identificados nos testemunhos do poço de Laras: Lycopodiopsis derbyi Renault; ? Thallites sp.; Pecopteris sp.; Vegetais indeterminados; Leinzia froesi Mendes; Paulocaris pachecoi Clarke; Amaralia paulistana Kegel; Liocaris huenei Beurlen; Clarkecaris brazilicus (Clarke); escamas e espinhas de peixes paleoniscídeos e ostracodes.

São feitas algumas considerações sobre a posição estratigráfica dos biota fósseis, do Grupo Passa Dois, tendo em vista as recentes pesquisas com o objetivo de estabelecer uma correlação entre os macro e microfósseis e um zoneamento bioestratigráfico dentro desse Grupo. Foram sugeridas, em caráter experimental para possíveis correlações, as seguintes zonas: Zona Pinzonella neotropica; Zona Lycopodiopsis derbyi; Zona I; Zona Pinzonella illusa; Zona II, dentro da Formação Estrada Nova. Dentro da Formação Irati, subjacente, com a inclusão do Membro Serra Alta, foram sugeridas: Zona III; Zona Leinzia froesi; Zona Barbosaia angulata; Zona Paulocaris pachecoi; Zona Mesosaurus brasiliensis com a Subzona Pygaspis brasiliensis e Zona Clarkecaris brazilicus.

* O presente trabalho é parte do apresentado, em 1976, no XXIX Congresso Brasileiro de Geologia realizado em Belo Horizonte, sob o título: Contribuição à geologia de subsuperfície e à paleontologia dos Grupos Passa Dois e Tubarão no Estado de São Paulo. 
Rev. IG, São Paulo, 1(1):15-34, jan./jun. 1980

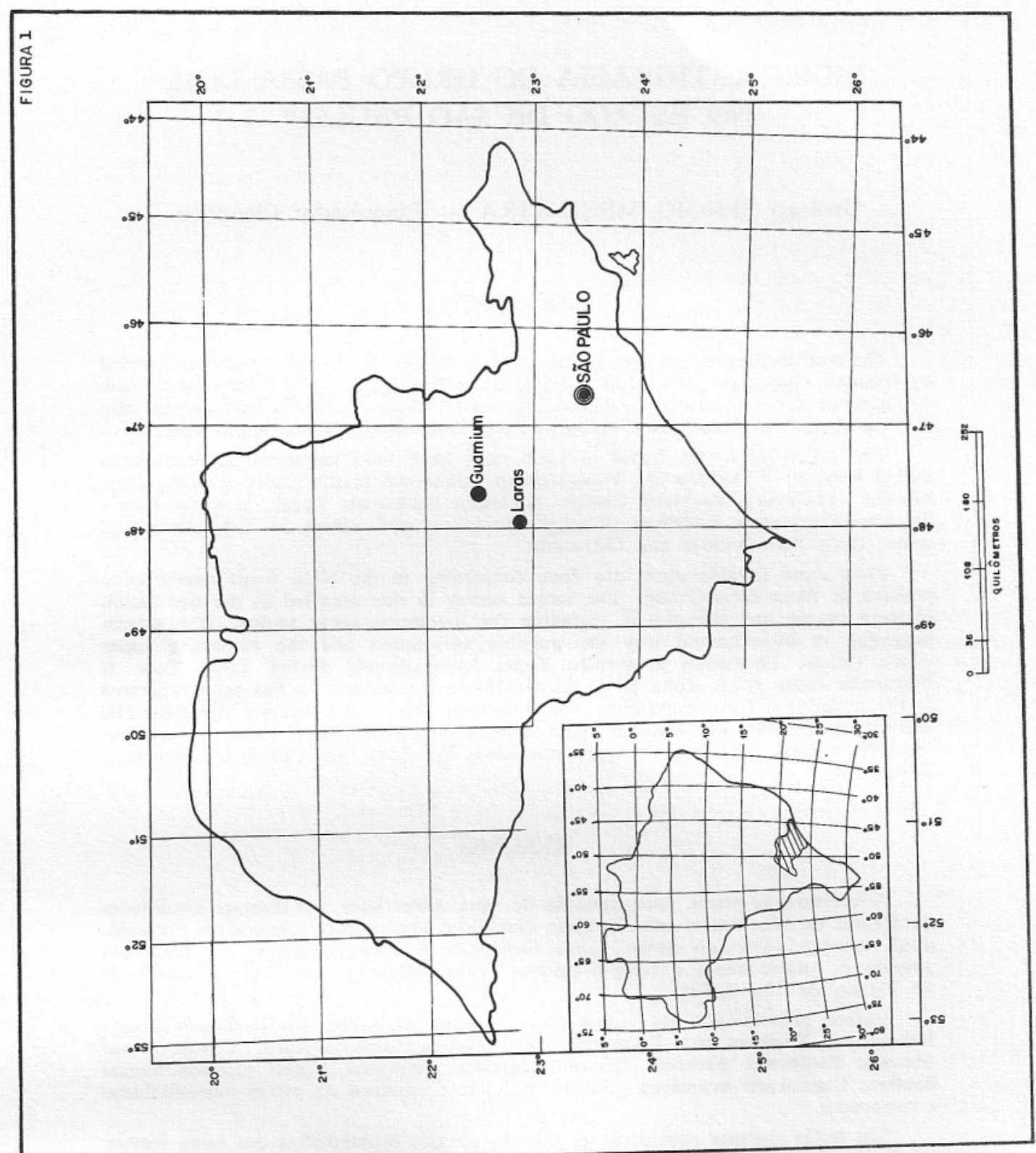




\section{INTRODUÇÃO}

Entre os diversos trabalhos de pesquisa do Instituto Geológico (antigo Instituto Geográfico e Geológico), da Coordenadoria da Pesquisa de Recursos Naturais, da Secretaria dos Negócios da Agricultura do Estado de São Paulo, inclui-se a de estratigrafia (litológica e biológica) de superfície e subsuperfície nas diversas formações sedimentares ocorrentes no Estado.

A pesquisa de subsuperfície é feita nos testemunhos obtidos nas perfurações de poços profundos, executados pelo Instituto Geológico para captação de água subterrânea. Assim, o objetivo do presente trabalho é divulgar os dados estratigráficos de subsuperfície, obtidos em sondagens executadas em Tanquinho, município de Piracicaba e Laras, município de Laranjal Paulista, todas localidades do Estado de São Paulo, contribuindo para maior conhecimento da bioestratigrafia do Grupo Passa Dois.

O encontro de fósseis, animais e vegetais, nos testemunhos de sondagem do poço Laras, município de Laranjal Paulista, trouxe novos dados sobre a distribuição dos mesmos na referida unidade litoestratigráfica.

\section{SITUAÇÃO GEOGRÁFICA}

Guamium (ex-Tanquinho) é um distrito pertencente ao município de Piracicaba. Encontra-se a $17 \mathrm{~km}$ ao $\mathrm{N}$ de Piracicaba e $18 \mathrm{~km}$ ao $\mathrm{S}$ de Rio Claro. Da capital paulista dista $170 \mathrm{~km}$. E somente servida por linha de ônibus. Aproximadamente a $10 \mathrm{~km}$ ao $\mathrm{N}$ situam-se as pedreiras de dolomito de Assistência, município de Rio Claro, explorado para corretivo de acidez do solo.

Laras, distrito de Laranjal Paulista está a $15 \mathrm{~km}$ ao NNW desta cidade que é servida pela FEPASA $(\mathrm{km} 185+478 \mathrm{~m})$ a partir de São Paulo.

As cidades encontram-se na área dos sedimentos paleozóicos constituindo uma das unidades com características geomorfológicas e geográficas próprias e que foi denominada como Depressão Periférica por Morais Rego, em 1932, e subdividida em três zonas por Deffontaines em 1935. (in ALMEIDA, 1964 p. 228).
Nos poços dos distritos de Guamium e Laras foram atravessados sedimentos do Grupo Estrada Nova e paralisada as sondagens no Grupo Tubarão, permitindo obter novos dados geopaleontológicos.

\section{ESTRATIGRAFIA}

O Grupo Passa Dois tem sido objeto de estudos estratigráficos por parte de inúmeros autores, nacionais e estrangeiros, com o objetivo de uma melhor compreensão do comportamento do mesmo, não só quanto às suas subdivisões como idade e correlação.

Enumerar a vastíssima literatura existente sobre o assunto, tornaria o presente trabalho muito longo e escaparia às finalidades do mesmo. Contudo, resumos do desenvolvimento sobre o conhecimento desse grupo poderão ser obtidos em MEZZALIRA, 1964 e 1971; MENDES, 1967; AMARAL, 1971; BIGARELLA, 1971, etc. Limitar-nos-emos, por isso, a citar os estudos mais recentes que vêm ao encontro do nosso objetivo.

O Grupo Passa Dois, para o Estado de São Paulo, é constituído por duas formações, que de cima para baixo são: Estrada Nova (= Corumbataí) e Irati.

A Formação Estrada Nova é aqui considerada indivisa, excluindo-se o Fácies Paranapanema (= Serra Alta) que será incluído na Formação Irati, como já sugerira MENDES et al. (1966, p. 40) e adotada por BIGARELLA (1971, p. 14-15) e FULFARO (1971, p. 7), em virtude da intercalação de camadas de "folhelhos" não betuminosos do tipo Serra Alta entre as camadas betuminosas da Formação Iratí. Esse fato já havia sido observado no Estado de São Paulo por MEZZALIRA (1952, 1965) e constituiu o chamado Fácies Ribeirão Grande, descrito por MENDES et alii. (1966).

A Formação Estrada Nova está aqui caracterizada por uma sequiência de siltitos, de cores variadas (pardo, vermelho, roxo, cinza, verde), arenitos, calcários, em parte oolíticos, e sílex, assentada concordantemente sobre a Formação Iratí. O seu contato superior com a Formação BotucatuPirambóia apresenta uma discordância erosiva e o plano de contato entre essas duas formações é irregular. 
A sua espessura que oscila em torno de 150 a $180 \mathrm{~m}$, com a passagem do Fácies Paranapanema (= Serra Alta) para a Formação Iratí, ficará diminuída para 120 a $150 \mathrm{~m}$ em vista deste "fácies" ter espessuras entre 30 e $40 \mathrm{~m}$, variando para mais nas sondagens executadas no interior da bacia sedimentar.

A Formação Iratí é constituída por uma sequiência de folhelhos pretos e pirobetunapanema de Mendes et alii. 1966)".

Para BIGARELLA (1971, p. 14) a subdivisão do Iratí em membros é conveniente e "na sequiência desta formação em São Paulo é também oportuna a inclusão de parte das camadas inferiores atribuídas à Formação Corumbataí. A inclusão destas camadas na Formação Iratí já foi sugerida por MENDES et alii. (1966, p. 40). Dessa forma, no norte do Paraná e São Paulo a Formação Iratí seria subdividida em três membros sendo o superior representado pela seqüência Serra Alta (= fácies Paraminosos alternando-se com dolomitos, siltitos cinzentos, sílex e, ocasionalmente, arenitos.

Quanto à inclusão do Membro Taquaral à sequiência da Formação Iratí, propugnado por MEZZALIRA desde 1957, é procedente e não fere o sentido original do termo de White, que incluía na secção original sedimentos similares (Membro Serra Alta) sobrepostos aos folhelhos pirobetuminosos. Embora os contatos sejam muitas vezes gradacionais difíceis de determinar, parece prática do ponto de vista estratigráfico, a separação da Formação Iratí em três membros distintos". (BIGARELLA, 1971, p. 13-14).

No Estado de São Paulo a primeira divisão proposta foi a de BARBOSA \& GOMES (1958), denominando a parte superior de Membro Assistência e a inferior de Taquaral. Seguiu-se outra proposta por MEZZALIRA (1971, p. 285-286) baseada nas características litológicas e biológicas e designadas de fácies argilo-carbonática (= Membro Assistência de Barbosa e Gomes); fácies síltico-argilosa (= fácies Ribeirão Grande de Mendes et al.); fácies dolomítica (= fácies Bairrinho de Mezzalira) constituindo elas a parte superior da Formação Iratí e, na parte inferior, a fácies síltico argiloso-arenosa (Membro Taquaral de Almeida \& Barbosa). BIGARELLA (op. cit. p. 11) ressaltou que a diferenciação entre os folhelhos do Serra Alta, dos situados entre as camadas pirobetuminosas e dos do Taquaral, é conseguida somente nos trabalhos de estratigrafia de campo, uma vez que apresentam "a mesma composição mineralógica e o mesmo aspecto físico, o que torna praticamente impossível sua separação sem o critério estratigráfico". Essa dificuldade tem sido sentida pelo A., que adotou em seus trabalhos de campo, o critério estratigráfico e paleontológico, pois no Estado, tem sido encontrado, até o momento, só bivalves no Serra Alta e o crustáceo Clarkecaris com restos de peixes no Taquaral, desconhecendo-se o conteúdo fossilífero dos folhelhos (siltitos) intermediários. BIGARELLA (op. cit. p. 15) propôs que a seqüência Iratí, para o norte do Paraná e São Paulo, fosse a seguinte, de cima para baixo:

F. Irati $\left\{\begin{array}{l}\text { Membro Serra Alta } \\ (=\text { Fácies Paranapanema }) \\ \text { Membro Assistência } \\ (=\text { membro oleígeno }) \\ \text { Membro Taquaral }\end{array}\right.$

Contudo, a subdivisão acima proposta e adotada neste trabalho, sofre algumas modificações, no que diz respeito às denominações dos membros e fácies, para o sul do Paraná, Santa Catarina e Rio Grande do Sul que não cabe aqui mencionar.

A espessura da Formação Irati no conceito antigo, é bastante variável e oscila entre 20 e $30 \mathrm{~m}$ (afloramentos), aumentando nas sondagens executadas mais para o centro da bacia, para até $50 \mathrm{~m}$ (AMARAL, 1971). Nas perfurações executadas pela PETROBRÁS, as espessuras variaram desde $3 \mathrm{~m}$ (Olímpia) até $50 \mathrm{~m}$ (Paraguaçu Paulista) (MEZZALIRA, 1964, p. 72).

Em trabalho posterior, MEZZALIRA (1971), apresentou os resultados de uma série de perfurações para captação de água e prospecção mineral, realizadas em toda a extensão do Irati, no Estado de São Paulo e que acusaram espessuras desde 2,50 m até 46,30 m excluindo-se o Membro Serra Alta. Este membro, nessas perfurações, atingiu espessuras variáveis entre 7 e $77 \mathrm{~m}$ sendo as mais comuns entre 20 e $40 \mathrm{~m}$ e, excep- 
cionalmente, duas únicas com $75 \mathrm{~m}$ e $77 \mathrm{~m}$, em Rio Claro e Anhembi, respectivamente.

Outros dados de perfurações referem-se às espessuras de 15 a $88 \mathrm{~m}$ para o Iratí em São Paulo (WASHBURNE, 1930; OPPENHEIN, 1934; MEZZALIRA, 1965 e PAIVA, 1975) e onde se verifica que as variações dessas espessuras estão condicionadas aos autores que interpretaram os perfis geológicos.

A formação jaz sem discordância erosiva sobre a Formação Tatuí, do Grupo Tubarão, muito embora, nessa transição, se faça presente, por vezes, uma camada conglomerática (seixos de sílex) e/ou arenito grosseiro, ambos atectônicos, contendo restos de peixes.

\section{GEOLOGIA DE SUBSUPERFICIE}

\section{Litoestratigrafia}

A divulgação dos dados obtidos nas novas perfurações, constitui uma das finalidades deste trabalho.

Poço profundo de Guamium (Tanquinho), município de Piracicaba, SP: O distrito de Guamium (Tanquinho) situa-se a meio caminho entre Piracicaba e Rio Claro e próximo às pedreiras de dolomito da Formação Irati, no bairro de Assistência.

Nos arredores ocorrem sedimentos argilo-arenosos, decompostos, de tonalidade vermelha, da Formação Iratí. Em cisternas abertas, na área, foram assinalados folhelhos amarelados, decompostos, com nódulos e "bonecas" de sílex, seguindo-se folhelhos escuros alternados com dolomitos. A espessura da referida formação oscila entre 15 e $25 \mathrm{~m}$, confirmada parcialmente pela perfuração de poço profundo em terras do Aziz Neme, a $50 \mathrm{~m}$ de pequeno córrego, e próximo da estrada que une a vila à rodovia asfaltada Piracicaba-Rio Claro.

Os dados principais do poço são:

$$
\begin{aligned}
& \text { Altitude }-575 \mathrm{~m} \\
& \text { Profundidade total }-172,30
\end{aligned}
$$

Perfil litoestratigráfico - segundo $\mathrm{S}$. Mezzalira.

\begin{tabular}{|c|c|c|c|}
\hline 0 & a & 11 & - Solo. \\
\hline 11 & $a$ & 24 & $\begin{array}{l}\text { - Sedimentos da Formação Irati, } \\
\text { com siltitos cinzentos na base. } \\
\text { Base da Formação Irati. }\end{array}$ \\
\hline 24 & a & 97 & $\begin{array}{l}\text { - Diabásio, granulação média a } \\
\text { grossa, fraturado e vesicular } \\
\text { entre } 33 \text { a } 34 \mathrm{~m} \text {. }\end{array}$ \\
\hline 97 & $a$ & 98,50 & $\begin{array}{l}\text { - Arenito esbranquiçado, ci- } \\
\text { mentado. }\end{array}$ \\
\hline 98,50 & a & 114 & $\begin{array}{l}\text { - Arenito e siltito esverdeado, } \\
\text { calcífero entre } 108 \text { a } 108,50 \mathrm{~m} \text {. } \\
\text { Grupo Tubarăo (Membro Ta- } \\
\text { tuí). }\end{array}$ \\
\hline 114 & $a$ & 115 & $\begin{array}{l}\text { - Arenito esverdeado e choco- } \\
\text { late. }\end{array}$ \\
\hline 115 & a & 140 & $\begin{array}{l}\text { - Siltito chocolate com partes } \\
\text { cimentadas por carbonatos; } \\
\text { partes mais argilosas e parte } \\
\text { conglomerática entre } 137,50 \text { a } \\
137,80 \mathrm{~m} \text {. }\end{array}$ \\
\hline 140 & a & 141 & $\begin{array}{l}\text { - Arenito conglomerático, cho- } \\
\text { colate. }\end{array}$ \\
\hline 141 & a & 142 & $\begin{array}{l}\text { - Arenito síltico argiloso, cin- } \\
\text { zento com parte conglomerá- } \\
\text { tica }(141,50 \text { a } 141,90 \mathrm{~m}) \text {. }\end{array}$ \\
\hline 142 & a & 144 & $\begin{array}{l}\text { - Não saiu testemunho. Na base } \\
\text { fragmento de arenito gros- } \\
\text { seiro. }\end{array}$ \\
\hline 144 & a & 146 & $\begin{array}{l}\text { - Arenito médio a grosso, con- } \\
\text { glomerático (145,50 a } 145,90) \text {. } \\
\text { Grupo Tubarão (Membro } \\
\text { Tupi). }\end{array}$ \\
\hline 146 & a & 153,80 & $\begin{array}{l}\text { - Arenito cinza-claro, friável; } \\
\text { médio a fino. Estrutura ma- } \\
\text { ciça. }\end{array}$ \\
\hline
\end{tabular}

\section{Profundidades (m)}

Poço profundo de Laras, município de Laranjal Paulista: Nos arredores desse distrito, de Laranjal Paulista, localizado na margem direita do rio Tietê, ocorrem sedimentos da Formação Estrada Nova representados, por siltitos, argilitos e sílex. O desnível topográfico, em relação ao leito do rio Tietê, é da ordem de $40 \mathrm{~m}$. Sobrejacentes aos termos litológicos da Formação Estrada Nova, aparecem sedimentos arenosos que a princípio foram classificados como pertencentes à Formação Botucatu e como tal mapeados na folha geológica de Piracicaba (MEZZALIRA, 1965). Contudo esses sedimentos são de idade mais recente e de origem aluvionar, confirmada pela testemunhagem do poço (areia, seixos de quartzo, quartzito e sílex), ora aberto, e acusando uma espessura de $10 \mathrm{~m}$. 
Ao longo das estradas de Laranjal Paulista-Taquaranxin-Laras (pela balsa) e Laranjal Paulista-Pederneiras-Laras foram encontrados inúmeros terraços antigos (Terciário?), com mais de uma dezena de metros de espessura, contendo grossos cascalhos de quartzo, quartzito e sílex, situados em nível entre 40 e $70 \mathrm{~m}$ acima do leito atual do rio Tietê.

É bem provável a existência de falhamento nas proximidades de Laras e, possivelmente, situa-se no leito do rio, uma vez que na sua margem esquerda estão os sedimentos aluvionares e à direita os da Formação Estrada Nova, com um desnível de 30 a $40 \mathrm{~m}$ indicando que o rejeito seria dessa ordem de grandeza.

$\mathrm{Na}$ rodovia de Laras a Laranjal Paulista passando pelos bairros Taquaranxin e Morro Alto, ocorrem siltitos arroxeados, arenitos cimentados da Formação Estrada Nova; folhelhos, calcários-dolomitos, sílex e "bonecas" de sílex, siltitos cinzentos (Membro Taquaral) da Formação Irati e siltitos e arenitos esverdeados do Tatuí (Grupo Tubarão) já nos vales dos ribeirões próximos àquela cidade. Antes do córrego Taquaranxin, nessa mesma rodovia, descreveu RIGBY (1968) novos fósseis vegetais associados com bivalves, procurando estabelecer uma distribuição vertical local e não regional por falta de melhores dados. Encontrou-se agora, em um nível de cerca de $20 \mathrm{~cm}$ acima do nível de Lycopodiopsis derbyi Renault, estabelecido por aquele autor, madeiras silicificadas referíveis a Tieteia singularis Solms Laubach e a "Dadoxylon".

Há vários anos atrás a PAMEC Ltda. perfurou, na margem direita do rio Tietê, um poço que atingiu $220 \mathrm{~m}$, mas cujos dados litológicos são desconhecidos.

$O$ poço recentemente aberto pelo Instituto Geológico a $300 \mathrm{~m}$, ao norte do primeiro poço, na bacia do ribeirão do Ponce, próximo ao grupo escolar, apresentou os seguintes dados:

\footnotetext{
Altitudes - $520 \mathrm{~m}$

Profundidade total $-200 \mathrm{~m}$

Perfil litoestratigráfico - segundo $\mathrm{S}$.

Mezzalira
}

\section{Profundidades (m)}

$$
\begin{aligned}
& \begin{array}{llll}
0 & \text { a } & 8 & \text { - Solo arenoso }
\end{array} \\
& 8 \text { a } 9 \text { - Seixos rolados de quartzo, }
\end{aligned}
$$

35,80 a 36 - Arenito esbranquiçado, parcialmente silicificado.

36 a 39 - Siltito avermelhado, maciço, laminação paralela a $38,50 \mathrm{~m}$; conglomerado intraformacional (sílex, calcário e argilito) passando a silex na base.

39 a 46 - Siltito avermelhado, maciço, passando a esverdeado com leitos argilosos intercalados.

46 a 50 - Siltito vermelho-arroxeado maciço, calcifero, passando a siltito creme com microleitos de calcita e seixos de sílex, acamamento irregular, alternando-se com siltito fino, maciço e calcífero. (Foto n. ${ }^{\circ}$ ).

50 a 52 - Siltito arroxeado, maciço, calcífero e com nódulos de silex, passando a silex na base.

52 a 53 - Siltito arroxeado, maciço, com Lycopodiopsis sp (3 níveis) seguindo-se em alternância, siltito marron com finas camadas calciferas, contendo seixos de sílex esbranquiçado provocando arqueamento da camada superior

53 a 102 - Siltito arroxeado, maciço; partes rítmicas (61-62 m); fenda ou falha preenchida por calcita e argila, $77 \mathrm{~m}$ (Foto n. ${ }^{\circ} 2$ ); siltito cinza e preto com deslisamentos (65-67 m); cinza-esverdeado $(69-72 \mathrm{~m})$ e com microestruturas $(81$ a $83 \mathrm{~m})$. Base da Formação Estrada Nova. Passagem para 0 Membro Serra Alta.

102 a 135 - Siltito cinzento-escuro, maciço, fratura concoidal; conglomerado intraformacional de seixos de argila distribuídos irregularmente na matriz, $\quad 121-122 \mathrm{~m} \quad(50 \mathrm{~cm}$ de espessura); leito cinza-claro com fóssil bivalve a $130 \mathrm{~m}$ ( $50 \mathrm{~cm}$ de espessura); cinza, conglomerático a $131 \mathrm{~m}$. Fendas preenchidas por calcita. Restos de peixes distribuídos 
em toda a extensão vertical deste siltito. Presença de pirita disseminada na massa sob forma cristalina e de nódulos. Passagem para o Membro Assistência.

a 136,40 - Folhelho síltico, cinzento-escuro e claro, calcífero, laminação paralela dando um aspecto de ritmicidade. Restos de crustáceos. Odor fétido.

136,40 a 151 - Dolomito cinza-claro; odor fétido; leitos silicificados e leitos com nódulos de sílex alternando-se com folhelho escuro contendo nódulos e seixos de sílex preto. Camadas de calcário de 5 a $30 \mathrm{~cm}$ de espessura e de folhelhos de 10 a $20 \mathrm{~cm}$ (Foto n. ${ }^{\circ}$ ). Fragmentos do bordo nucal de crustáceos fósseis, nos dolomitos silicificados e Bilobites no folhelho preto $(149 \mathrm{~m})$.

151 a 152 - Dolomito contendo microleitos escuros (betume?) emprestando à rocha um aspecto "várvico", com alternância de camadas claras e escuras. Presença de microfalha. (Foto n. ${ }^{\circ}$ ).

152 a 153,20 - Dolomito esbranquiçado contendo restos fósseis de crustáceos, Liocaris sp.

153,20 a 155 - Siltito, cinzento, calcifero; fraturas verticais preenchidas; passando a arenoso na base.

155 a 156,00 - Folhelho preto com finos leitos arenosos, esbranquiçado, passando a pirobetuminoso de cor castanha, com seixos de sílex irregularmente distribuídos. Laminação plano-paralela horizontal. Restos de Peixes no folhelho preto. Os seixos provocam perturbações nas camadas $(155,30 \mathrm{~m})$.

156 a 165 - Dolomito creme, noduloso, seixos e nódulos de sílex alternando-se com folhelho preto-castanho pirobetuminoso contendo também nódulos e seixos de sílex. No folhelho castanho observa-se fina laminação plano-paralela horizontal devido ao betume singenético segundo AMARAL (1971). Observam-se zonas de deslisamento ou acomodação por compactação $(160 \mathrm{~m} ; 162$ e $163 \mathrm{~m})$.

165 a 167,20 - Folhelho preto pirobetuminoso passando a siltito argiloso cinzento, piritoso, contendo fragmentos de calcita singenética (?) e de sllex distribuídos irregularmente na matriz (166,50 a $167,20 \mathrm{~m})$ Passagem para o Membro Taquaral.

167,20 a 174,40 - Siltito argiloso, cinzento-escuro, tornando-se mais arenoso; laminação paralela entre 169,00 e 169,50 , retornando ao siltito argiloso. Fósseis crustáceos (telson) e, escamas de peixes paleoniscídios.

174,40 a 174,50 - Conglomerado cinza, seixos de silex de vários tamanhos, parte arredondados e parte angulosos. Restos de peixes (escamas e fragmentos silicificados). O siltito arenoso cinza-esverdeado subjacente tem laminação irregular. Passagem para o Grupo Tubarão (Membro Tatuí).

174,50 a 193 - Siltito arenoso, cinza-esverdeado; laminação paralela horizontal em parte; fratura concoidal em outras; microestruturas.

193 a 199 - Siltito cinzento, argiloso, fratura concoidal, maciço, piritoso e com estratificação irregular aos $198 \mathrm{~m}$.

199 a 199,50 - Arenito conglomerático cinza-esverdeado, com seixos de sílex angulosos de diâmetros de $0,001 \mathrm{~m}$ a $0,5 \mathrm{~m}$; na base, acamamento irregular.

199,50 a 200 - Siltito cinza-esverdeado contendo leitos e nódulos de sílex cinza-claro.

\section{CONTEUDO PALEONTOLÓGICO}

Somente no poço de Laras, município de Laranjal Paulista, foram encontrados fósseis que contribuíram para um melhor conhecimento da sua distribuição vertical dentro do Grupo Passa Dois. Os fósseis identificados são:

Profundidades (m)

a) Lycopodiopsis derbyi - 52 a 52,50 Renault (Foto n. 7) (3 níveis)

b) Thallites? sp. - 52 a 52,50

c) Pecopteris sp. (Foto n. 8) $-52,50$

d) Vegetal indeterminado - 52,50

e) Samaropsis sp. $\quad-52,50$

f) Ostracódies $\quad-52,50$

g) Leinzia froesi Mendes - 130

h) Paulocaris pachecoi Clarke (folhelho escuro)

$-135,20$ a 135,70

i) Paulocaris sp. (fragmentos do bordo nu- $-136,60 ; 137$ e cal; aparecem no dolomito silicificado). $-138,25$ 
j) Amaralia paulistana

Kegel (Foto n. 5) - 149

k) Liocaris huenei Beurlen

1) Fragmentos de Liocaris $\mathrm{sp}$.

m) Escamas de peixes paleoniscídios -155

n) Clarkecaris brazilicus (Clarke) (télson)

o) Fragmento ósseo (?) de Peixe

p) Escamas e espinhas de peixes paleoniscídios (Foto n. 6) -174

\section{- BIOESTRATIGRAFIA}

\section{- Considerações Gerais.}

A literatura, sobre os mais diversos aspectos geológicos, paleontológicos, paleoecológicos e estruturais, etc., da bacia do Paraná é muito grande, porém poucas são as publicações que se preocupam em estabelecer critérios sobre a distribuição vertical dos fósseis. Neste capítulo será feita uma tentativa de, baseado nos recentes trabalhos e no conhecimento do A., estabelecer zonas fossilíferas como hipótese de trabalho, para possíveis correlações, com as dos demais Estados do sul do país.

As duas primeiras tentativas feitas nesse sentido, devem-se a Von HUENE (1928), para a Formação Estrada Nova, quando estabeleceu dois horizontes fossilíferos com suas faunas características e MEZZALIRA (1954, p. 169) para a Formação Iratí, quando propôs uma sequiência bioestratigráfica baseada nos crustáceos dessa formação.

Com o desenvolvimento das pesquisas paleontológicas no Estado de São Paulo, novos jazigos, com novos espécimes, foram assinalados, procurando os autores precisar e ampliar a sua distribuição vertical, destacando-se os trabalhos de MENDES (1944, 1944a, 1945, 1949, 1952 e 1962); MEN-

GRUPO PASSA
DOIS $\quad\left\{\begin{array}{l}\text { Formação Rio do Rasto } \\ \text { Formação Estrada Nova } \\ \text { Formação Irati }\end{array}\right.$

Os macrofósseis de mais fácil identificação, no campo, já apresentam, no Grupo Passa Dois, uma distribuição mais conhe-
DES \& MEZZALIRA (1946); MEZZALIRA (1952, 1952a, 1957, 1959, 1965, 1966, 1968, 1971); BEURLEN (1953); LANDIM (1970); ALMEIDA \& BARBOSA (1953); FULFARO (1964; 1970); DAEMON \& QUADROS (1970); a RUNNEGAR \& NEWELL (1971).

DAEMON \& QUADROS (Rel. 1969 e public. 1970) baseados em esporos Monoletes, Saccites, Monocolpates, e formas do gênero Tasmanites spp apresentaram uma divisão bioestratigráfica dos sedimentos da bacia do Paraná, baseada em amostras colhidas em poços profundos e afloramentos.

Tomaram esses autores como "datum" o intervalo $\mathrm{K}$ por estar presente em todos os poçcs e afloramentos examinados, sendo que no Estado de São Paulo, somente 3 (três) poços, dos diversos perfurados pela PETROBRÁS SA, acusaram a presença desses microfósseis. São os de Lins (2Li.1SP); Assistência, mun. de Rio Claro, SP (1-As-1-SP) e Paraguaçu Paulista (2 PP st-1-SP). De afloramentos, somente foram examinadas rochas dos arredores de Itu, SP.

Litoestratigraficamente a partir do subintervalo $\mathrm{L}_{2}$ temos o Grupo Passa Dois e do intervalo $G$ até o subintervalo $L_{1}$, o Grupo Tubarão. Contudo NORTHFLEET et al. (1969) sugeriram algumas modificações no que diz respeito à cronoestratigrafia.

A tentativa de correlacionar os microfósseis identificados por DAEMON \& QUADROS (op. cit.) com os macrofósseis do Grupo Passa Dois ficou prejudicada, uma vez que examinando-se o perfil do poço de Paraguaçu Paulista, as profundidades das amostras de calha, $2118 \mathrm{~m}$ e $2163 \mathrm{~m}$, correspondem aos subgrupos Guatá e Itararé, respectivamente. A amostra (test. 12) não indica a profundidade, daí ser difícil precisar sua posição para correlação. O Grupo Passa Dois, no poço em apreço, está assim delimitado:

\footnotetext{
- Prof. $1250 \mathrm{~m}$ a $1445 \mathrm{~m}$.

- Prof. $1445 \mathrm{~m}$ a $1925 \mathrm{~m}$, com intercalação de diabásio entre 1640 e 1710 . Prof. $1925 \mathrm{~m}$ a $2050 \mathrm{~m}$ (incluindo o Serra - Alta com $76 \mathrm{~m}$ de espessura).
}

cida, embora a posição dos níveis sofram variações conforme a região estudada. Há, contudo, necessidade de uma revisão com- 
pleta, no que diz respeito à divisão litoestratigráfica, espessuras dos "facies" e formações, bem como da sua paleofauna e paleoflora.

A distribuição malacofaunística atualmente conhecida, deste grupo e comparada com a apresentada por RUNNEGAR \& NEWELL (1971), na qual o Membro Serra Alta, ainda, faz parte da Formação Estrada Nova, está assim constituída:

Baseado em: MENDES (1952, 1962, 1963); MEZZALIRA (1957, 1958, 1959); LANDIM (1970); FULFARO $(1964,1970)$.

1. Não identificável no Estado.

2. Zona Pinzonella neotropica e Jacquesia brasiliensis

Cowperesia anceps (Reed)

Jacquesia brasiliensis (Reed)

Naiadopsis lamellosus Mendes

Pinzonella neotropica (Reed)

Plesiocyprinella carinata Holdhaus

Roxoa intrigans Mendes

3. Zona Pinzonella illusa e Plesiocyprinella carinata

Cowperesia anceps (Reed)

Coxesia mezzalirai Mendes (não aparece em Angatuba, SF)

Ferrazia cardinalis Reed (também em Mato Grosso)

Ferrazia cf cardinalis Reed

Jacquesia brasilensis Reed

Pinzonella illusa Reed (freqüente também em Mato Grosso)

Plesiocyprinella carinata Holdhaus (não aparece em Angatuba, SP)

Roxoa corumbataiensis Mendes (idem)

Terraia aequilateralis Mendes (freqüente também em Mato Grosso)

Holdhausiella elongata (Holdhaus) também em Mato Grosso

Casterella gratiosa Mendes

Angatubia cowperesioides Mendes (desconhecida em Rio Claro, SP)

Cowperesia camposi Mendes

Favalia arcuata Mendes (comum às localidades em Angatuba, Rio Claro, SP)

Othonella araguaiana Mendes (comum no Estado de Mato Grosso)

Espinhas do tipo ctenacantídio - Escamas.

4. Zona Barbosaia angulata e Holdhausiella almeidai

Anthraconaia?

Barbosaia angulata Mendes

Casterella of C. camargoi Beurlen

Ferrazia cardinallis Reed

Ferrazia simplicicarinata Mezzalira

Holdhausiella almeidai Mendes

Holdhausiella elongata Mendes

Leinzia froesi Mendes

Pinzonella cf $\mathbf{P}$. illusa Reed

Plesiocyprinella cf P. carinata Holdhaus

Rioclaroa lefevrei Mezzalira

Terraia aequilateralis Mendes

Leinzia gigantea Mendes

Escamas de Coelacanthida e Ostracoda.
Segundo RUNNEGAR \& NEWELL (1971)

1. Assembléia Leinzia similis (MENDES)

? Barbosaia sp.

Leinzia similis (Holdhaus)

Oliveiraia pristina (Reed)

? Pyramus emerita (Reed)

Terraia altissima (Holdhaus)

Bivalves mitilideos

Dendropupa sp.

(Provavelmente só no Paraná e Santa Catarina).

2. Assembléia Pinzonella neotropica (MENDES) Pyramus anceps (Reed)

Jacquesia brasiliensis (Reed) - muito comum

Naiadopsis lamellosus Mendes

Pinzonella neotropica (Reed)

Roxoa intrigans (Mendes)

Casterella gratiosa Mendes

Ferrazia cardinalis (Reed)

Jacquesia elongata (Holdhaus) - rara

"Pleurophorus" bipleura (Reed)

Terraia lamegoi

3. Assembléia Pinzonella illusa Reed

Pyramus anceps (Reed)

Coxesia mezzalirai Mendes

Ferrazia cardinalis Reed

Pinzonella illusa Reed

Plesiocyprinella carinata Holdhaus

Roxoa corumbataiensis Mendes

Terraia aequilateralis Mendes

Jacquesia elongata (Holdhaus)

Casterella gratiosa Mendes

? Pyramus cowperesioides (Mendes)

? P. camposi (Mendes)

Jacquesia arcuata (Mendes)

Othonella araguaiana Mendes.

4. Assembléia Leinzia froesi Mendes

? Anthraconaia sp

Barbosaia angulata Mendes

Casterella cf C. camargoi Beurlen

Ferrazia cardinallis Reed

Ferrazia simplicicarinata Mezzalira

Jacquesia almeidai (Mendes)

Jacquesia elongata (Mendes)

Leinzia froesi Mendes

Pinzonella of illusa Reed

Plesiocyprinella of $\mathbf{P}$. carinata Holdhaus

Rioclaroa lefevrei Mezzalira

\section{ZONAS BIOESTRATIGRÁFICAS}

Para a distribuição dos biota fósseis e constituição das zonas bioestratigráficas adotou-se como critério, o estabelecimento dos limites máximo e mínimo de ocorrência dos níveis fossilíferos, de acordo com os estudos dos autores já mencionados.

Algumas dificuldades foram sentidas devido à diversificação dos critérios por eles adotados, uma vez que uns consideravam a distribuição vertical a partir do topo da Formação Irati e, outros, a partir da base da Formação Botucatu e, mesmo assim, as divergências foram muito peque- 
nas. As altitudes não foram consideradas, pois poderiam levar a conclusões errôneas, em vista da influência de outros fenômenos geológicos.

As espessuras das formações do Grupo Passa Dois são muito variáveis e devido a essa extrema variabilidade foram adotadas, não a média, mas sim as mais constantes, com pequena margem de oscilação.

Naturalmente a distribuição tem caráter experimental, até que novos dados possam sugerir modificações que visem aperfeiçoá-la para possível correlação com a bioestratigrafia dos Estados do sul do Brasil embora haja diversificação dos biota fósseis.

Adotou-se a seguinte divisão estratigráfica:

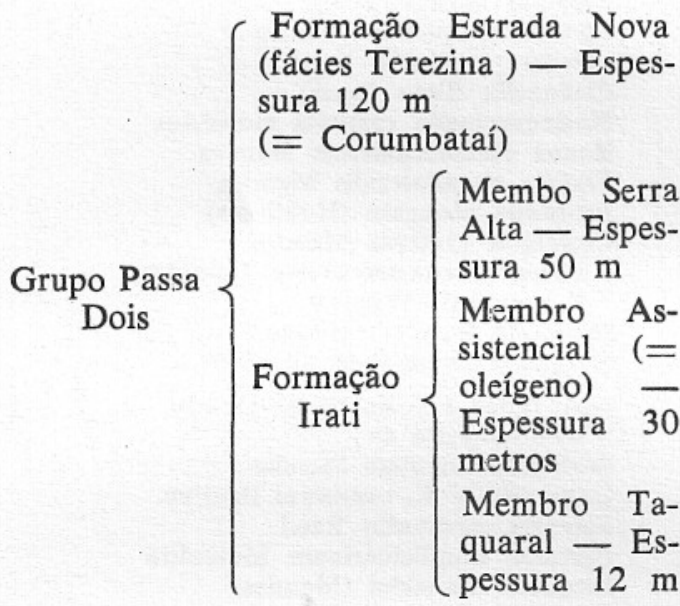

Baseado na coluna acima considerou-se a distribuição espacial vertical dos fósseis, para a Formação Estrada Nova (= Corumbataí), a partír da Formação Botucatu + Pirambóia e, para os do Irati, a partir do seu topo.

Então a distribuição bioestratigráfica esquematizada para o Grupo Passa Dois, no Estado de São Paulo, é a seguinte:

Formação Estrada Nova - Espessura variável entre 120 a $150 \mathrm{~m}$, considerando-se aqui a de $120 \mathrm{~m}$, à vista dos dados mais recentes disponíveis.

1. Zona Pinzonella neotrópica (Reed). Ocorre de $0 \mathrm{~m}$ a $18 \mathrm{~m}$ a partir do topo da formação. O nível mais baixo conhecido é de $18 \mathrm{~m}$, podendo ocorrer outros níveis, a $3 \mathrm{~m}, 10 \mathrm{~m}$ e $18 \mathrm{~m}$ na região de Rio Claro-Corumbataí e de $5 \mathrm{~m}$ e $10 \mathrm{~m}$ na região da Santa Cruz das Palmeiras e Descalvado respectivamente. Situam-se, nesta zona, os seguintes fósseis:

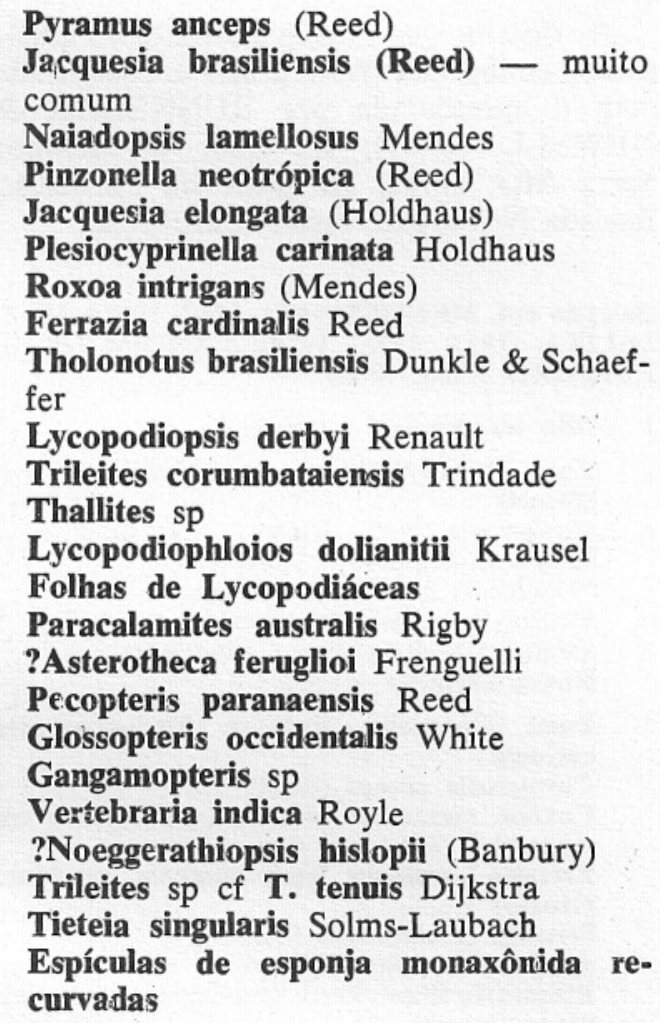

2. Zona Lycopodiopsis derbyi Renault situa-se entre $20 \mathrm{~m}$ a $35 \mathrm{~m}$. Este vegetal tem seu nível mais constante a $29 \mathrm{~m}$ abaixo da Formação Botucatu, embora apareça, também, na zona anterior. Os fósseis desta são:
Pyramus sp
Pinzonella sp
Jacquesia $\mathrm{sp}$
Ferrazia cardinalis Reed
Acantholeaia regoi Almeida
Lycopodiopsis derbyi Renault
Walchia? sp (ramos de coníferas indet., segundo YOSHIDA)
Troncos silicificados de Coníferas
Trileites corumbataiensis Trindade
Espículas de esponja monaxônida recur- vadas.

E possível que alguns dos vegetais relacionados na Zona Pinzonella neotrópica, possam ocorrer, também, nesta zona.

3 - Zona I - Situa-se entre 35 a $50 \mathrm{~m}$. Da região de Fartura, SP, são referidos 
bivalves pertencentes à Jacquesia, sp. Terraia, sp e Plesiocyprinella sp.

Espículas de esponja monaxônida recurvadas.

4 - Zona Pinzonella illusa Reed - Situada entre 50 a $75 \mathrm{~m}$ sendo o seu nível mais comum entre 55 e $70 \mathrm{~m}$. E a melhor conhecida e mais fossilífera. Estão presentes os seguintes fósseis:

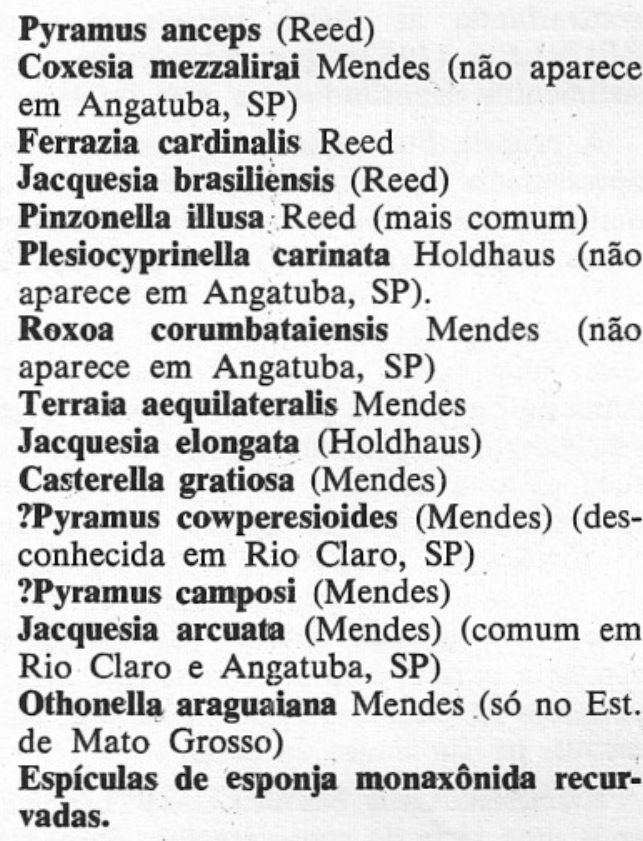

ALMEIDA \& BARBOSA (1953) situam nesta zona:

Dadoxylon nummularium Maniero; Dadoxylon sp (= Woodworthia); Tieteia singularis Solms Laubach e Lycopodiopsis derbyi Renault.

5 - Zona II $=$ Colocada entre 75 e $100 \mathrm{~m}$. Há referências ao encontro de Pyramus $\mathrm{sp}$ a $80 \mathrm{~m}$ (Charqueada, SP) e de espículas de esponja monaxônida recurvadas.

6 - Zona Glossopteris - Sigillaria Anotada entre 100 a $120 \mathrm{~m}$ com os seguintes fósseis:

Glossopteris angustifolia var. taeniopteroides SEWARD

Sigillaria brarddi Brong. var. menardii

Marchantites? sp

Stigmaria $\mathrm{sp}$

\section{Esporos e folíolos de Felicíneas \\ Pyramus sp \\ Pinzonella sp}

Espículas de esponja monaxônida recurvadas.

Ainda, na Formação Estrada Nova temos girogonites de Caráceas referidos por RAGONHA \& SOARES (1974) e os microfósseis de DAEMON \& QUADROS (1970), não relacionados aqui, por falta de melhor conhecimento sobre seus níveis.

\section{- Formação Iratí:}

1 - Zona III - Está situada entre 0 e $15 \mathrm{~m}$ do topo da formação e, até o momento, desconhece-se seu conteúdo fossilífero.

2 - Zona Leinzia froesi Mendes. Colocada entre $15 \mathrm{~m}$ e $35 \mathrm{~m}$ e os seus fósseis comuns são:

Leinzia froesi Mendes

Leinzia gigantea Mendes

Jacquesia elongata (Mendes)

Jacquesia almeidai (Mendes)

Cesterella cf. C. camargoi Beurlen

Ferrazia cardinalis Reed

Ferrazia símplicicarinata Mezzalira

Pinzonella cf $\mathbf{P}$. illusa Reed

Plesiocyprinella of $\mathbf{P}$. carinata Holdhaus

Rioclaroa lefevrei Mezzalira

Terraia aequilateralis Mendes

Barbosaia angulata Mendes

Bivalves indeterminados

Restos e fragmentos de peixes

Ostrácodes

Esfenofílea (ramo)

Espículas de esponja monaxônida recurvadas.

3 - Zona Barbosaia angulata Mendes - Situada na seqüência de 35 a $50 \mathrm{~m}$ e são conhecidos os seguintes fósseis:

?Anthraconaia sp

Leinzia froesi Mendes

Barbosaia angulata Mendes

Jacquesia elongata (Mendes)

Jacquesia almeidai (Mendes)

Bivalves indeterminados (da região de

Itaí, e Paranapanema, SP)

Concostracos (?)

Ostrácodes

Restos e Escamas de Coelacanthidae

Espículas de esponja monaxônida recurvadas. 
4 - Zona Paulocaris pachecoi Clarke. Colocada de $50 \mathrm{~m}$ a $60 \mathrm{~m}$ e seus fósseis são:

Paulocaris pachecoi Clarke

Amaralia paulistana Kegel

Fragmentos de Mesosaurus (?) sp.

Espinhas, escamas e fragmentos ósseos de peixes

Espículas de esponja monaxônida recurvadas.

5 - Zona Mesosaurus brasiliensis Mc Gregor - Situa-se, em seguida, entre $60 \mathrm{~m}$ e $80 \mathrm{~m}$ contendo os seguintes fósseis:

Liocaris huenei Beurlen

Liocaris angusta Beurlen

Stereosternum tumidum Cope

Mesosaurus brasiliensis Mc Gregor

Brazilosaurus sãopaulensis Shikama \&

Ozaki

Parataxopitys americana (Milanez \&

Dolianiti)

Polysolenoxylon whitei (Maniero)

Solenopitys paulistana Krausel \& Dolianiti

\section{Esporos de Gymnospermas}

?Glossopteris $\mathrm{sp}$

Restos e fragmentos de peixes.

Espículas de esponjas monaxônida recurvadas.

Com a ocorrência, de somente, em Limeira, SP, do crustáceo Pygaspis brasiliensis Beurlen, em folhelhos pretos, na parte basal do Membro Assistência (últimos $5 \mathrm{~m}$ ) sugere-se a criação de uma subzona (subzona Pygaspis brasiliensis Beurlen) constituída por aquele fóssil associado a espículas de esponjas monaxônida recurvadas e escamas de peixes paleoniscídios.

6. Zona Clarkecaris brazilicus (Clarke) - Situa-se em seguida, entre $80 \mathrm{~m}$ e $92 \mathrm{~m}$ contendo:

Clarkecaris brazilicus (Clarke)

Escamas e restos de peixes paleoniscídios ocorrentes em diversos níveis

Espículas de esponja monaxônida recurvadas.

\section{PALEOAMBIENTE}

A princípio, com base nos dados paleontológicos (identificação dos fósseis como marinhos) e geológicos (grande extensão das camadas e aparente constância geológica), os sedimentos do Estrada Nova (= Corumbataí) foram considerados de origem marinha.

Os estudos posteriores de LEANZA (1948), MENDES (ops. cits.) e MEZZALIRA (1957, 1964), e inúmeros outros autores, baseado nas características e tipos de associações fossilíferas e nas estruturas sedimentares passaram a admitir um ambiente continental para a referida formação, contrariando as idéias iniciais e a de BEURLEN (1953) que considerava esses sedimentos depositados em mar interior.

A própria Formação Irati, também, tem apresentado inúmeras discussões sobre seu ambiente ser marinho ou continental, opinando AMARAL (1971) pela presença de um grande lago, em comunicação para o mar, principalmente na região sul da bacia, com suas águas se movimentando para sudoeste onde estão presente registros desta paleocorrente aquática, explicando em virtude disto a ausência de fósseis marinhos em locais distantes do acesso. A presença de Clarkecaris brazilicus Clarke, no Membro Taquaral, indicaria ambiente de água-doce. Os demais fósseis não permitem chegar a uma conclusão satisfatória, mas a presença de madeiras fósseis indicaria, pelo menos, proximidades da costa.

RUNNEGAR \& NEWELL (1971, p. 22), após uma série de considerações, de ordem paleontológica, paleogeográfica e paleoambiental sugerem um estudo comparativo do Grupo Passa Dois, com a atual região Pontian-Caspian, devido a similaridade entre os ambientes de deposição existentes entre os dois e, opinam pelo ambiente marinho.

KEITH (1969) encontrou ampla variação na relação isotópica $\mathrm{C}^{13} / \mathrm{C}^{12}$, em inúmeras amostras de calcário e dolomito do Irati e, em comparação com os recentes carbonatos sugeriu, exceto por uma amostra, que "the Irati Formation was deposited in a marine to marginal marine environment" (IN RUNNEGAR \& NEWELL, 1971 p. 22). Estudos mais recentes (DE GIOVANNI, et alii, 1971) baseado nas relações $\mathrm{C}^{13} / \mathrm{C}^{12}$ e $\mathrm{O}^{18} / \mathrm{O}^{16}$ indicam condições ambientais diferentes. As relações isotópicas do banco dolomítico do Membro Assistência sugerem ambiente de água-doce, enquanto que os dolomitos da parte superior, que se encontram alternados com folhelhos, ambiente de água salgada. 
DAEMON \& QUADROS (1960-70, p. 378) opinaram que durante os intervalos $K$ e $\mathrm{L}$ a bacia do Paraná atingiu uma fase de equilíbrio e que o clima tinha sofrido mudanças: "quente e seco em certas regiões com possíveis áreas mais úmidas, sendo que a tendência a aridez tornou-se mais acentuada, provavelmente, no Grupo Rio do Rasto", devido a presença dos sedimentos vermelhos que parecem corroborar esse fato.

Os estudos das estruturas sedimentares, análises químicas, petrográficas, mineralógicas e isotópicas dos calcários oolíticos da Formação Estrada Nova, da região de Taguaí, SP sugeriram que a deposição desses calcários se processou em ambiente marinho ou lacustrino, relativamente agitado e submetido a intensa evaporação. (SUGUIO et alii, 1974 p. 142).

Naturalmente o estudo supra não poderia ser generalizado para toda a Formação Estrada Nova, mas a variabilidade litológica e paleontológica encontrada no pacote sedimentar do Grupo Passa Dois sugeriria mudanças (marinhos e continentais) e variações climáticas sazonais no decorrer da deposição dos seus sedimentos, comprovadas pela presença das diferentes estruturas (gretas de contração, laminação rítmica e marcas onduladas, etc) e das várias associações da paleofauna com a paleoflora. 
QUadro bioestratigrafico Para O estado de São PaUlo

\begin{tabular}{|c|c|c|c|c|c|c|c|c|c|}
\hline \multirow{2}{*}{\multicolumn{3}{|c|}{ LITOESTRATIGRAFIA }} & \multirow{3}{*}{ LITOLOGIA } & \multicolumn{3}{|c|}{ BIOESTRATIGRAFIA } & \multirow{2}{*}{\multicolumn{3}{|c|}{ CRONOESTRATIGRAFIA }} \\
\hline & & & & \multirow{2}{*}{$\frac{\text { Mierofósseis }}{\text { ZONAS }}$} & \multicolumn{2}{|c|}{ Microfósseis } & & & \\
\hline Grupo & Formação & Membro & & & $\begin{array}{l}\text { Inter- } \\
\text { valos }\end{array}$ & $\begin{array}{l}\text { Subin- } \\
\text { tervalos }\end{array}$ & Andar & Série & Sistema \\
\hline \multirow{13}{*}{$\begin{array}{l}n \\
0 \\
0 \\
0 \\
4 \\
0 \\
\infty \\
\infty \\
4 \\
4\end{array}$} & \multirow{6}{*}{ 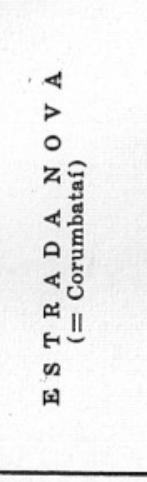 } & \multirow{6}{*}{$\begin{array}{l}\text { Terezina } \\
\text { (?) }\end{array}$} & \multirow{6}{*}{$\begin{array}{l}\text { Siltitos, argilitos (verde, roxo, verme- } \\
\text { lho, pardo e amarelo) e arenitos con- } \\
\text { tendo cimento calcíero e ou silicoso. } \\
\text { Calcário } \\
\text { Coquina } \\
\text { Sílex } \\
\text { Espessura - } 120 \mathrm{~m} .\end{array}$} & PINZONELLA NEOTROPICA (Reed) & \multirow{13}{*}{ L } & \multirow{13}{*}{$\mathrm{L}_{\mathrm{q}}$} & \multirow{13}{*}{$\begin{array}{l}0 \\
z \\
4 \\
4 \\
z \\
\mathbb{z} \\
N \\
\mathbb{N} \\
\mathbb{Z}\end{array}$} & \multirow{13}{*}{ 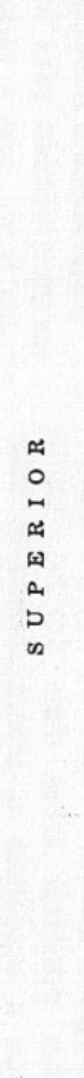 } & \multirow{13}{*}{ 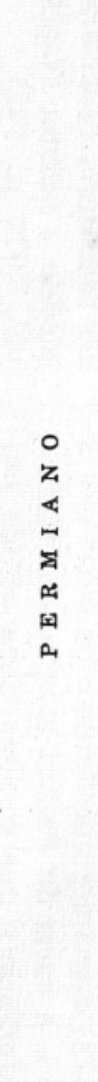 } \\
\hline & & & & LYCOPODIOPSIS DERBYI Renault & & & & & \\
\hline & & & & I & & & & & \\
\hline & & & & PINZONELLA ILLUSA (Reed) & & & & & \\
\hline & & & & II & & & & & \\
\hline & & & & GLOSSOPTERIS - SIGILLARIA & & & & & \\
\hline & \multirow{7}{*}{$\begin{array}{l}\text { H } \\
\& \\
\text { \& } \\
H\end{array}$} & \multirow{3}{*}{$\begin{array}{l}\text { Serra } \\
\text { Alta }\end{array}$} & \multirow{3}{*}{$\begin{array}{l}\text { Siltitos argilosos com partes arenosas, } \\
\text { cinza escuro a claro. } \\
\text { Fratura concoidal. } \\
\text { Espessura }-50 \mathrm{~m} .\end{array}$} & III & & & & & \\
\hline & & & & LEINZIA FROESI Mendes & & & & & \\
\hline & & & & BARBOSAIA ANGULATA Mendes & & & & & \\
\hline & & \multirow{3}{*}{$\begin{array}{l}\text { Assis- } \\
\text { tência } \\
(=\text { Oleí- } \\
\text { geno })\end{array}$} & \multirow{3}{*}{$\begin{array}{l}\begin{array}{l}\text { Folhelhos pirobetuminosos. } \\
\text { alternando-se com folhelhos } \\
\text { castanhos. }\end{array} \\
\text { Dretomitos } \\
\text { Siltitos cinzentos. } \\
\text { Silex preto. } \\
\text { Espessura }-30 \mathrm{~m} \text {. }\end{array}$} & PAULOCARIS PACHECOI Clarke & & & & & \\
\hline & & & & $\begin{array}{l}\text { MESOSAURUS BRASILIENSIS } \\
\text { Mc Gregor }\end{array}$ & & & & & \\
\hline & & & & Pygaspis brasiliensis Beurlen & & & & & \\
\hline & & Taquaral & $\begin{array}{l}\text { Siltitos cinzentos, arenito e conglome- } \\
\text { rado na base. } \\
\text { Espessura }-20 \mathrm{~m} .\end{array}$ & $\begin{array}{l}\text { CLARKECARIS BRAZILICUS } \\
\text { (Clarke) }\end{array}$ & & & & & \\
\hline
\end{tabular}


DISTRIBUIÇÃO DOS FÓSSEIS POR ZONAS BIOESTRATIGRÁFICAS DO GRUPO PASSA DOIS (PERMIANO SUP.) DO ESTADO DE SÃO PAULO

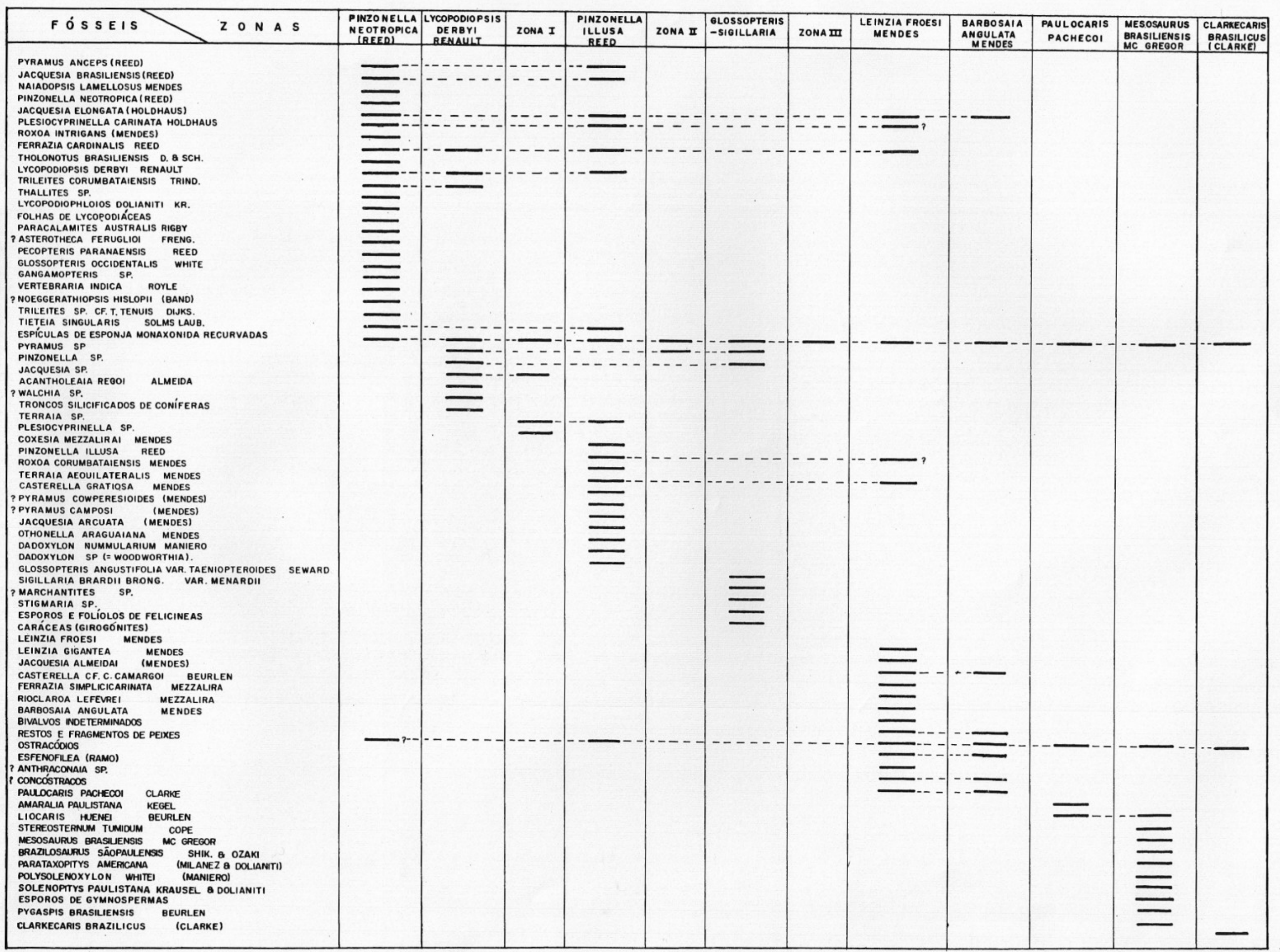


Rev. IG, São Paulo, 1(1):15-34, jan./jun. 1980

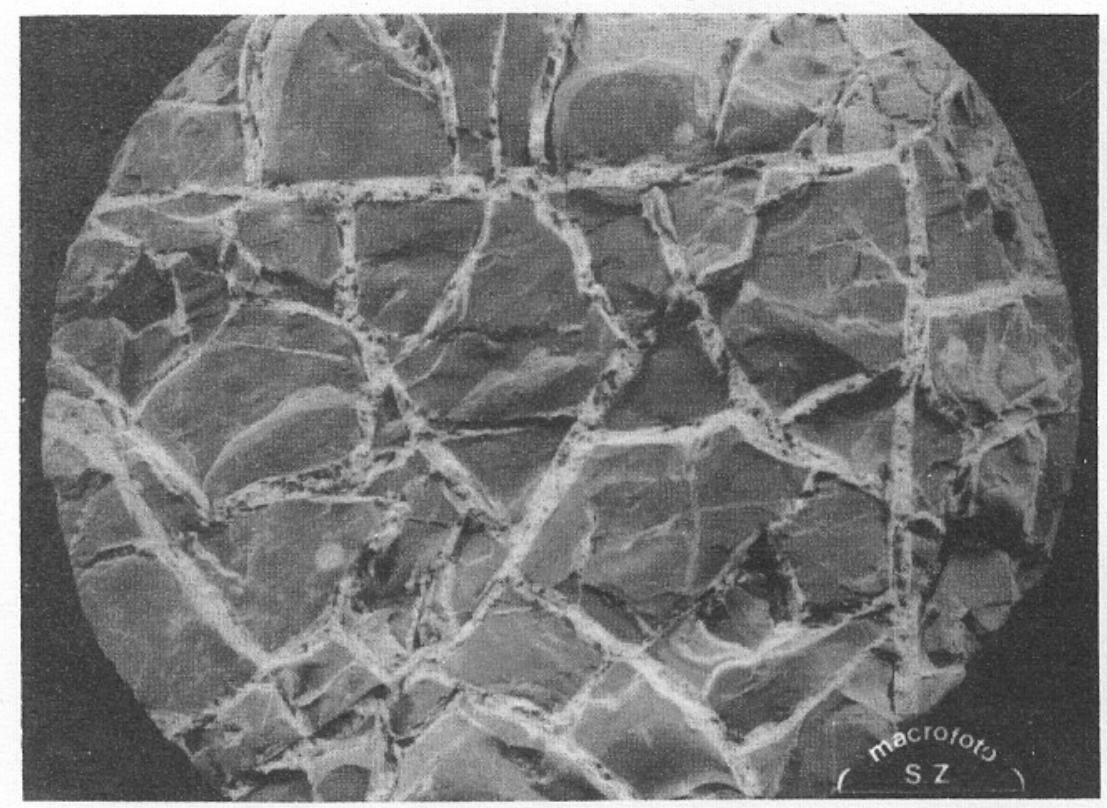

Foto n. 1 - Gretas de contração. Formação Estrada Nova. Poço n. 1; prof. 17,50 m. Laras, mun. de Laranjal Paulista, SP.

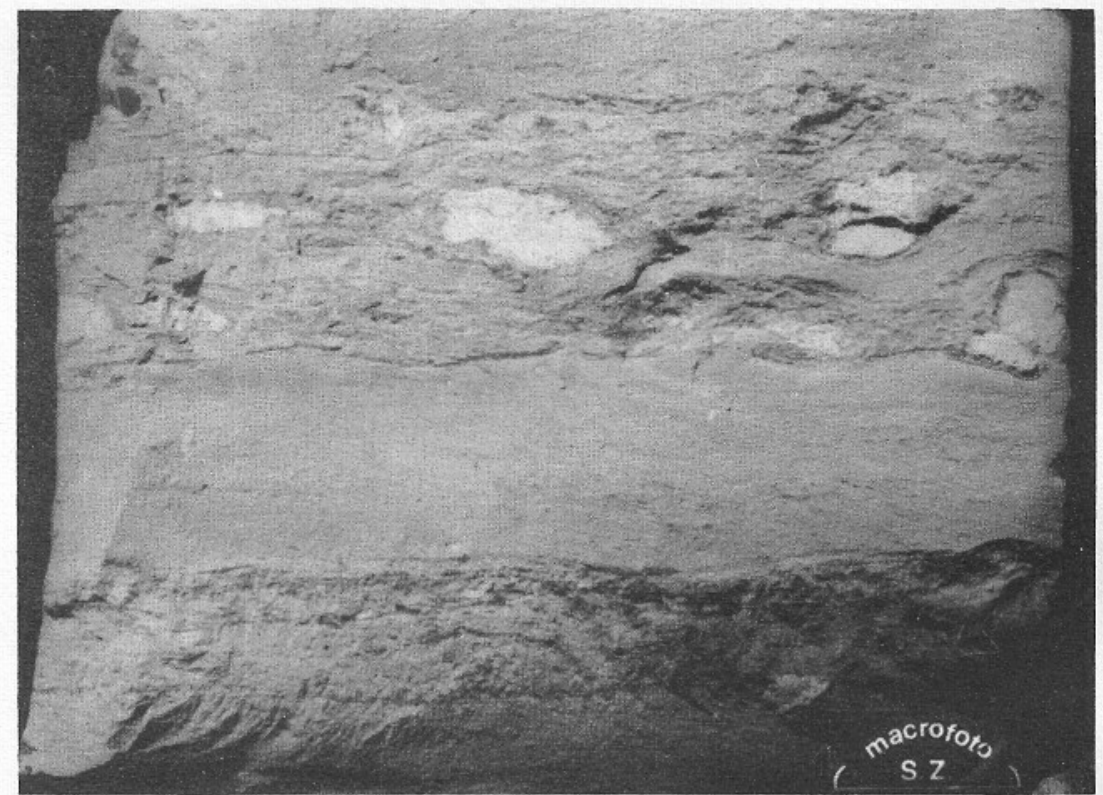

Foto n. 2 - Sedimentação cíclica. Siltito com microleitos de calcita e com seixos de silex; acamamento irregular alternando-se com siltito fino e calcífero, maciço. Formação Estrada Nova. Poço n. 1, prof. 47 m. Laras, mun. de Laranjal Paulista, SP. 
Rev. IG, São Paulo, 1(1):15-34, jan./jun. 1980

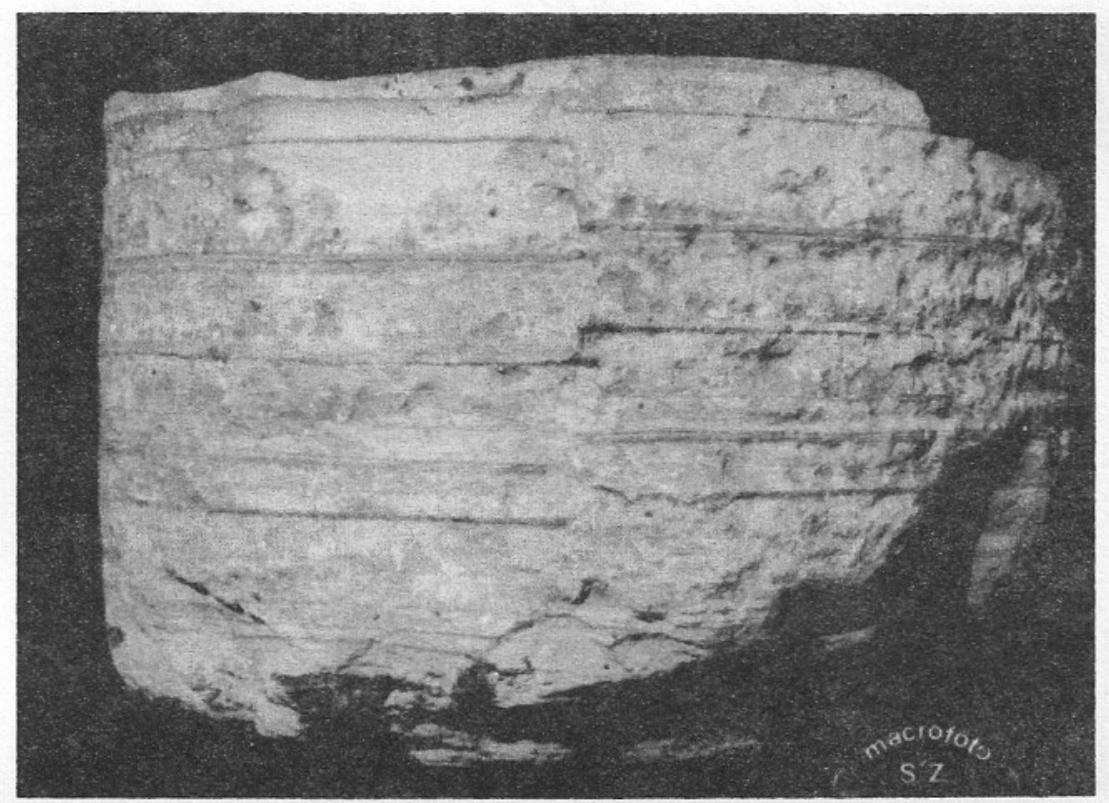

Foto n. 3 - Dolomito mostrando ritmicidade devido a intercalações de leitos argilosos escuros (betume?). Microfalha. Formação Irati. Poço n. 1, prof. $152 \mathrm{~m}$. Laras, mun. Laranjal Paulista, SP.

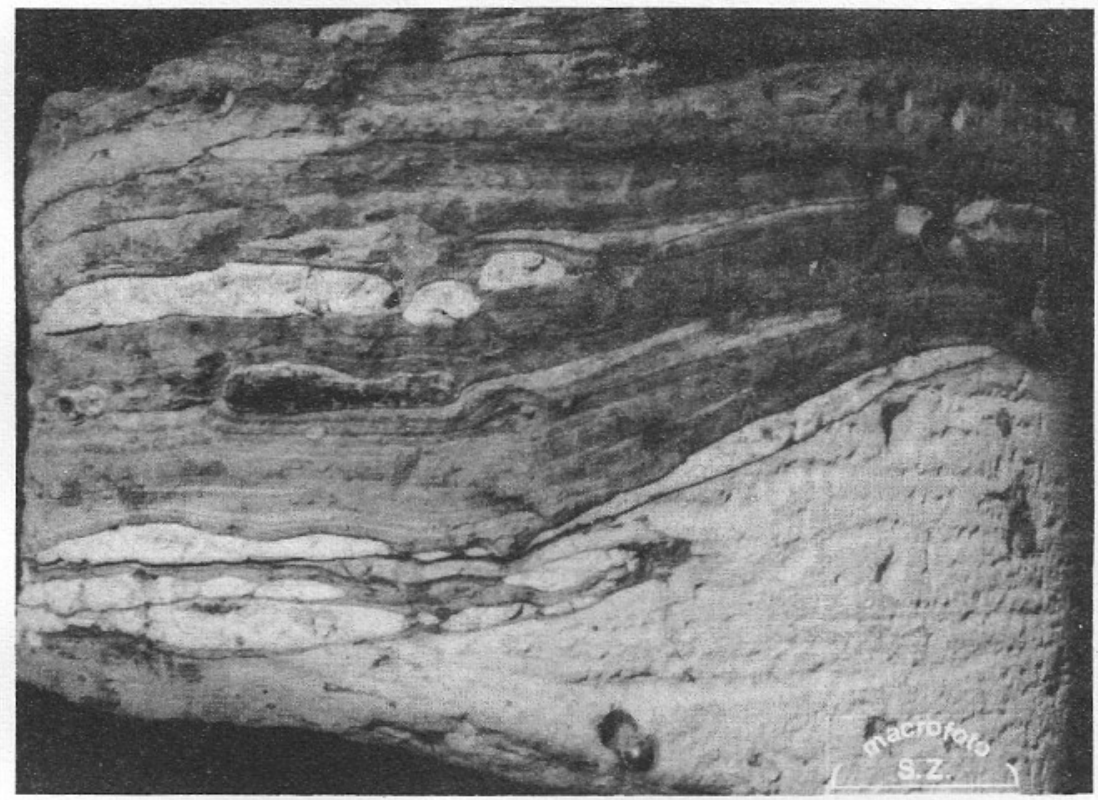

Foto n. 4 - Folhelho preto, com leitos e nódulos de silex e acamamento irregular. Na base dolomito cinzento com nódulos de silex. Formação Irati (Membro Assistência). Poço n. 1, prof. $147 \mathrm{~m}$. Laras, mun. de Laranjal Paulista, SP. 
Rev. IG, São Paulo, 1(1):15-34, jan./jun. 1980

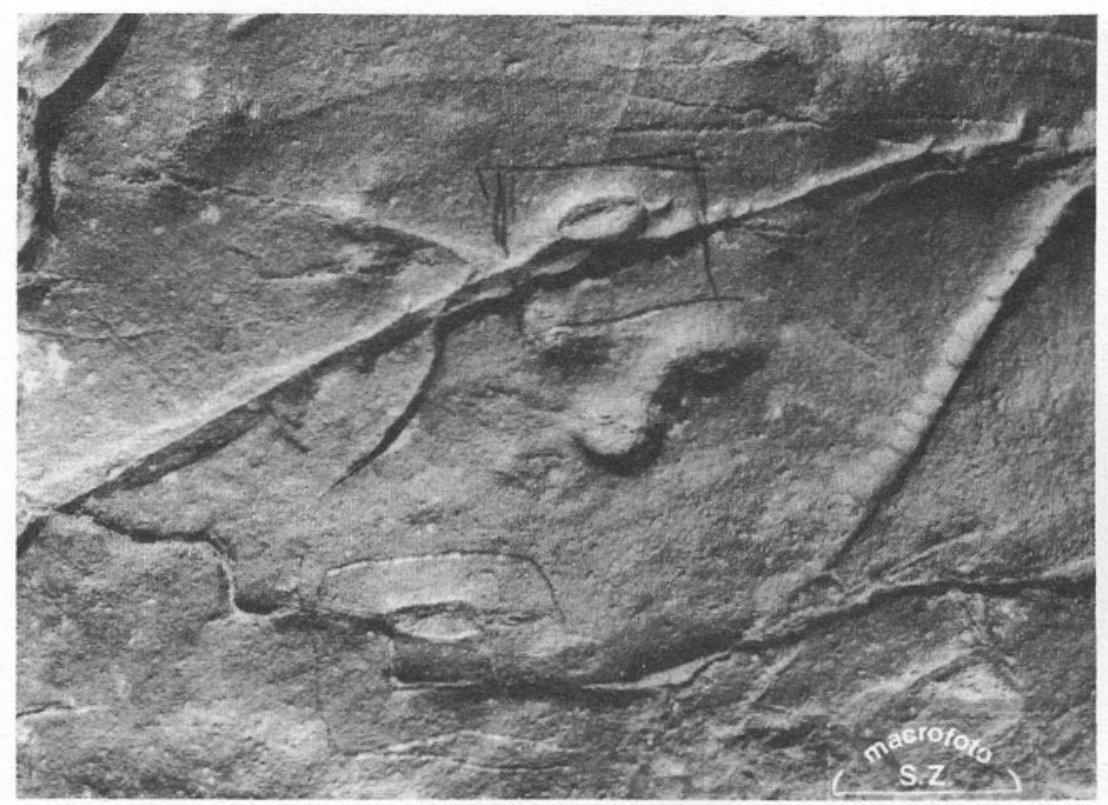

Foto n. 5 - Amaralia paulistana Kegel. Folhelho preto. Formação Irati (Membro Assistência). Poço n. 1, prof. $149 \mathrm{~m}$. Laras, mun. Laranjal Paulista, SP.

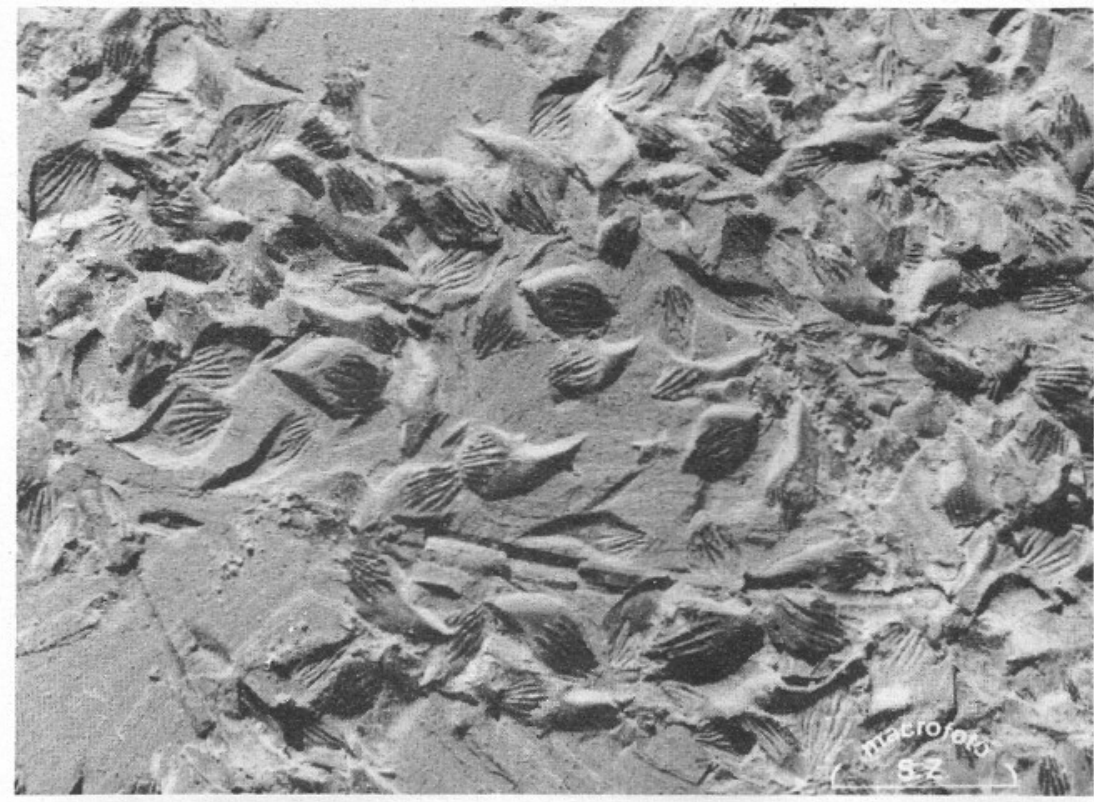

Foto n. 6 - Escamas e espinhas de peixes Paleoniscídios. Siltito cinzento. Formação Irati (Membro Taquaral). Poço n. 1, prof. $174 \mathrm{~m}$. Laras, mun. de Laranjal Paulista, SP. 
Rev. IG, São Paulo, 1(1):15-34, jan./jun. 1980

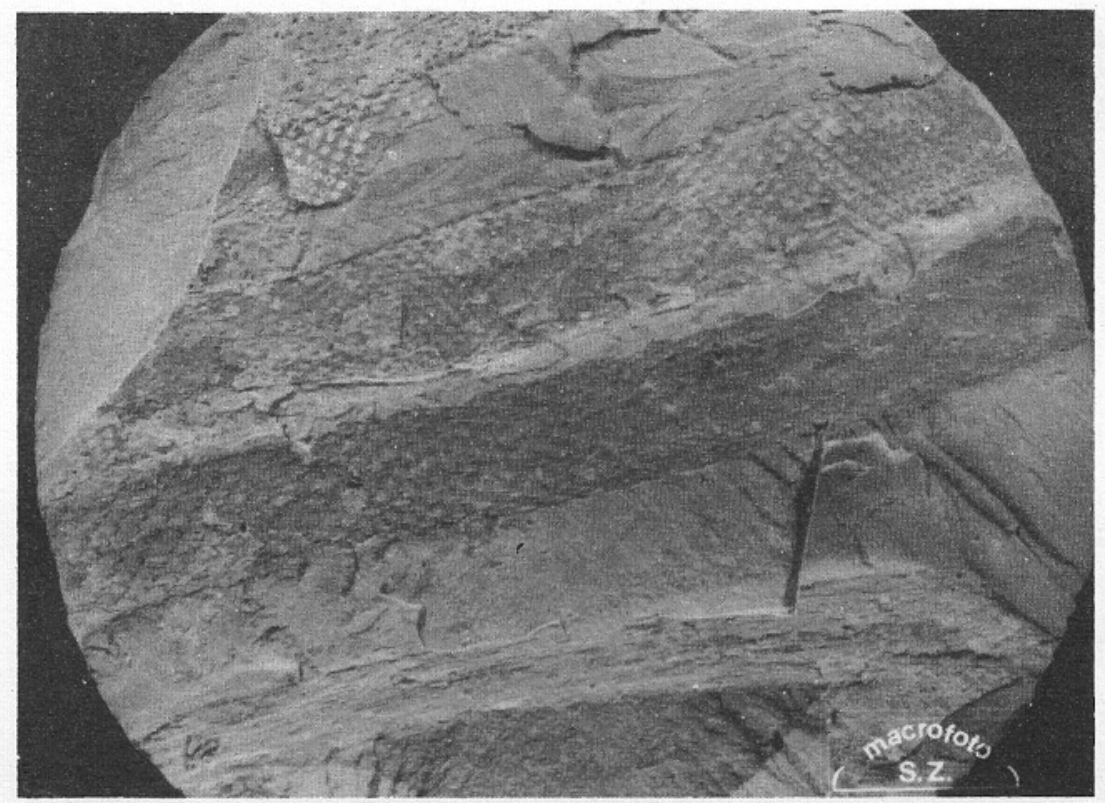

Foto n. 7 -- Lycopodiopsis derbyi Renault; ?Thallites sp. Formação Estrada Nova. Poço n. 1, prof. 52 a $52,50 \mathrm{~m}$. Laras, mun. Laranjal Paulista, SP.

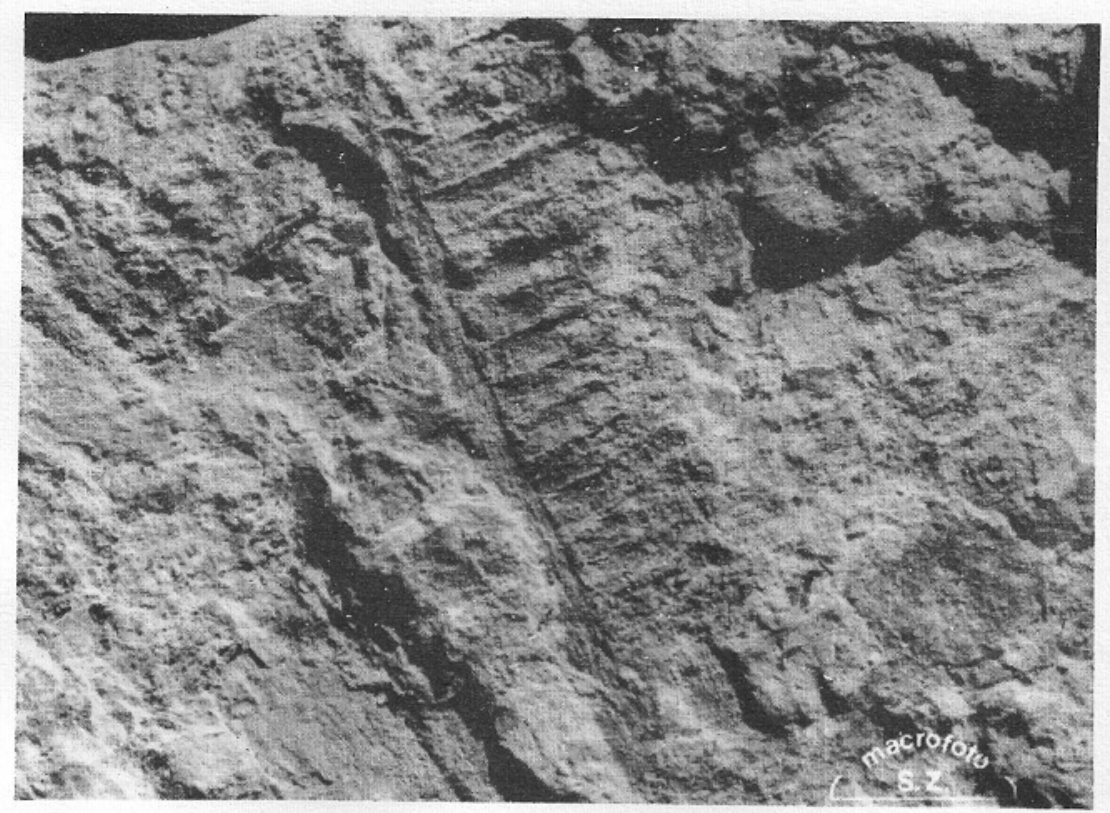

Foto n. 8 - Pecopteris sp. - Formação Estrada Nova. Poço n. 1, prof. 52,50 m. Laras, mun. Laranjal Paulista, SP. 
Rev. IG, São Paulo, 1(1):15-34, jan./jun. 1980

\section{AGRADECIMENTOS}

O Autor externa os seus agradecimentos aos Srs. Pedro Pacchiela Comério, do Instituto Geológico, da Coordenadoria da Pesquisa de Recursos Naturais da Secretaria da Agricultura, e, Saulo Zucchello pela execução das fotografias que ilustram este trabalho.

\section{BIBLIOGRAFIA}

ALMEIDA, F. F. M. DE - 1950 - Acantholeaia, um novo gênero de Leaiadidae. Rio de Janeiro, DNPM., DGM. 6p. il. (Notas Prels. e Ests., n. 51)

- -1964 - Fundamentos geológicos do relevo paulista. In: São Paulo. Instituto Geográfico e Geológico. Geologia do Estado de São Paulo. São Paulo. p.169-263, il. (Bol. n. ${ }^{\circ}$ 41)

_ — \& BARBOSA, O. - 1953 Geologia das quadrículas de Piracicaba e Rio Claro, Estado de São Paulo. Rio de Janeiro, DNPM., DGM. 96p. il. (Bol., n. ${ }^{\circ} 143$ )

AMARAL, S. E. - 1971 - Geologia e petrologia da Formação Irati (Permiano) no Estado de São Paulo. Bol. Inst. de Geociências e Astr., São Paulo, 2:(3-82)

BARBOSA, O. \& GOMES, F. A. - $1958-$ Pesquisas de petróleo na Bacia do rio Corumbataí, Estado de São Paulo. Rio de Janeiro, DNPM., DGM. 40p. il. (Bol., n. ${ }^{\circ}$ 171)

BEURLEN, J. - 1953 - As faunas de lamelibrânquios do sistema gonduânico no Paraná. Curitiba, F. W. Lange. p.107-136, estampas 1-7. / Volume comemorativo do $1 .^{\circ}$ Centenário do Estado do Paraná/

BIGARELLA, J. J. - $1971-$ Geologia da Formação Irati. In: Simpósio sobre Ciência e Tecnologia do Xisto, Curitiba, 1971. Conferências do Simpósio sobre Ciência e Tecnologia do Xisto, 1971. Curitiba, Paraná. Rio de Janeiro, Acad. Bras. de Ci. p.1-79.

DAEMON, R. F. \& QUADROS, L. P. - 1970 - Bioestratigrafia do neopaleozóico da bacia do Paraná. In: Congresso Brasileiro de Geologia, 24. ${ }^{\circ}$, Brasília. Anais. p.359-414.

DE GIOVANNI, W. F. et alii - 1974 - Usual isotopic composition of carbonates from the Irati Formation, Brazil. Bull. Geol. Soc. of Amer., Boulder, Colorado, 85(1):41-44, Jan. il.

FULFARO, V. J. - 1964 - A Formação Corumbataí nos arredores de Conchas, Estado de São Paulo. Bol. Soc. Bras. de Geol., São Paulo, 13(1-2):43-53, il.

\footnotetext{
- 1970 - Contribuição à geologia da região de Angatuba, Estado de São Paulo. Rio de Janeiro, DNPM., DGM. 83p. il. sapa. (Bol., n. ${ }^{\circ} 253$ )
}

- - 1971 - A evolução tectônica e paleográfica da bacia sedimentar do Paraná pelo "Trend surface analysis". São Paulo, USP, Esc. de Eng. de São Cirlos (Geologia, n. ${ }^{\circ}$ 14)
HUENE, F. VON - 1928 - Aphorisme über die stratigraphie des brasilianischen Staates São Paulo. Centr. für Mineral., Geol. und Pal., Abt. A Jg., Stuttgart, p. 524-531, 2 estampas.

KEGEL, W. - 1967 - Rastos do grupo dos Bilobites da Formação Irati, S. Paulo. Rio de Janeiro, DNPM., DGM. 4p. (Notas Prel. e Ests., n. ${ }^{\circ}$ 136)

KEITH, M. L. - 1969 - Isotopic composition of carbonates from the Karroo and comparison with the Passa Dois Group of Brazil. In: Symposium I.U.G.S., B. Aires, 1971. p. 775-778.

LANDIM, P. M. B. - $1970-$ O Grupo Passa Dois (P. ${ }^{\circ}$ ) na bacia do rio Corumbataí, SP. Rio de Janeiro, DNPM., DGM. 103p. il. (Bol., n. ${ }^{\circ}$ 252)

LEANZA, A. F. - 1948 - El llamado triassico marino del Brasil, Paraguay, Uruguay y Argentina. Rev. Assoc. Geol. Argent., B. Aires, 3(3):219-443. estampas.

MENDES, J. C. - 1944 - Posição estratigráfica de Lycopodiopsis derbyi Renault. Anais da Acad. Bras. de Ci., Rio de Janeiro, 16(2): 137-138.

— — 1944a — Lamelibrânquios triássicos de Rio Claro, Estado de São Paulo. São Paulo, USP. FFCL. 74p. 2 estampas. (Bol., n. ${ }^{\circ} 45$ - Geol., n. ${ }^{\circ}$ 1)

- - 1946 - Novos lamelibrânquios fósseis da Série Passa Dois, sul do Brasil. Rio de Janeiro, DNPM., DGM. 40 p. (Bol., n. ${ }^{\circ} 133$ )

\& MEZZALIRA, S. - 1946 - Posição estratigráfica dos novos horizontes com vegetais fósseis da Formação Estrada Nova. Rio de Janeiro, DNPM., DGM. 4p. 5 figs. (Notas Prel. e Ests., n. ${ }^{\circ}$ 30)

- - 1952 - A Formação Corumbataí na região do rio Corumbataí; estratigrafia e descrição dos lamelibrânquios. São Paulo, USP. FFCL. 119p. 3 estampas. (Bol., n. ${ }^{\circ} 145-$ Geol. n. ${ }^{\circ} 8$ )

- -1962 - Lamelibrânquios permianos do cólito de Angatuba, Estado de S. Paulo, Formação Corumbataí. Bol. Soc. Bras. de Geol., S. Paulo, 11(1): 37-45, 2 estampas. nos do Estado de Mato Grosso, Formação Estrada Nova. Bol. Soc. Bras. de Geol., São Paulo, 12(1-2):57-64.

- et alii - 1966 - A Formação Irati (Permiano) e fácies associadas. Bol. Soc. Bras. de Geol., S. Paulo, 15(3):23-43. 
- -1967 - The Passa Dois Group. In: Simpósio Internacional de Estratigrafia e Paleontologia do Gondwana, $1 .^{\circ}$, Curitiba, 1967. Problems in Brazilian Gondwana... Curitiba, Inst. de Geol., Univ. Fed. do Paraná. p.119-166, estampas 41-61.

MEZZALIRA, S. - 1952 - Alguns dados sobre água subterrânea no Estado de São Paulo. O IGG, S. Paulo, 10(3-4):233-244.

MEZZALIRA, S. - 1952 - Clarkecaris, novo gênero de crustáceo Syncarida do Permiano. Bol. Soc. Bras. de Geol., S. Paulo 1(1):4651,3 estampas.

- - 1954 - Novas ocorrências de crustáceos fósseis da Formação Irati no sul do Brasil. In: Lange, F. W. Paleontologia do Paraná... Curitiba, Comissão de Comemorações do Centenário do Paraná. p. 165-173, 9 estampas. novas da Série Passa Dois na região Limeira-Rio Claro-Piracicaba. Bol. Soc. Bras. de Geol., S. Paulo, 6(2):37-58, 2 estampas.

- -1958 - Dados sobre água subterrânea, nas Séries Passa Dois e Tubarão no Estado de S. Paulo. Bol. Soc. Bras. de Geol., S. Paulo, 7(1):49-73.

- 1959 - Nota preliminar sobre as recentes descobertas paleontológicas no Estado de S. Paulo no período 1958-1959. S. Paulo, Inst. Geogr. Geol. p. 1-9 (Notas Prévias, n. 2)

- -1964 - Grupo Estrada Nova. In: São Paulo. Instituto Geografico e Geológico. Geologia do Estado de São Paulo. p. 63-84. (Boletim n. ${ }^{\circ} 41$ )

1965 - Descrição geológica e geográfica das folhas de Piracicaba e São Carlos, SP. São Paulo, Inst. Geogr. e Geol., 2 folhas geológicas. (Bol. n. ${ }^{\circ} 43$ )

- - 1966 - Considerações sobre novas ocorrências fossilíferas no Estado de São Paulo. Anais Acad. Bras. de Geol., Rio de Janeiro, 38(1):65-72. São Paulo. S. Paulo, Instituto Geográfico e Geológico. 132p. (Boletim, n. ${ }^{\circ} 45$ )

fície, na região de Charqueada de subsuperSão Paulo, 20:65-72.
- Contribuição ao conhecimento de geologia de subsuperfície e da paleontologia da Formação Irati, no Estado de S. Paulo. Anais da Acad. Bras. de Ci., Rio de Janeiro, 43:273-336, Supl.

NORTHFLEET, A. A. et alii - $1969-$ Reavaliação dos dados geológicos da bacia do Paraná. Bol. Téc. da Petrobrás, Rio de Janeiro, 12(3):291-346, jul./set.

OPPENHEIM, V. - 1934 - Rochas gondwânicas e geologia do petróleo do Brasil meridional. Rio de Janeiro, DNPM. SFPM 129p. il. (Bol., n. ${ }^{\circ}$ )

PAIVA, G. de - 1975 - História da campanha de sondagens para pesquisa de petróleo na área de São Pedro, SP. 1921-1934. S. Paulo, Inst. Geogr. e Geol. 58p.

RAGONHA, E. W. \& SOARES, P. C. -1974 - Ocorrência de carófitas fósseis na Formação Estrada Nova (P), em Anhembi, SP. In: Congresso Bras. de Geol., 28. ${ }^{\circ}$, Porto Alegre. Resumo das Comunicações. Porto Alegre. p. 380-381. (Bol., n. ${ }^{1}$ )

RIGBY, J. F. - 1968 - New fossil plant locality near Laras, state of S. Paulo. In: Congr. Bras. de Geol., 22..$^{\circ}$ Belo Horizonte. p. 201-208.

RUNNEGAR, B. \& NEWELL, N. D. - 1971 - Caspian-like relict molluscan fauna in the South American Permian. Bull. Amer. Mus. Nat. History., N. York, 146 art (1): 5-66.

SHIKAMA, T. \& OZAKI, H. - 1966 - On a reptillian skeleton from the Palaeozoic formation of San Paulo., Brazil. Trans. Proc. Palaent. Soc. Japan, N.S. 61 Dec.: 351-358. pls. 38-39.

SUGUIO, K. et alii - 1974 - Calcários oolí ticos de Taguai, SP., e seu possível significado paleoambiental na deposição da Formação Estrada Nova. Rev. Bras. de Geociências, São Paulo, 4(3):142-167.

TRINDADE, N. M. - 1969 - Megásporos Permianos da Formação Corumbataí, Estado de S. Paulo. Anais da Acad. Bras. de Ci., Rio de Janeiro, 41(3):415-420.

WASHBURNE, C. - 1930 - Petroleum geology of State of S. Paulo. S. Paulo, Comissão Geográfica e Geológica. 272 p. (Bol., n. ${ }^{\circ}$ 22) 